\title{
Increased Cycling Efficiency of Lithium Anodes in Dimethyl Sulfoxide Electrolytes For Use in Li-O 2 Batteries
}

\author{
Matthew Roberts, ${ }^{, z}$ Reza Younesi," Will Richardson, Jia Liu,** Torbjörn Gustafsson,"* \\ Jiefang Zhu, ${ }^{*}$ and Kristina Edström*
}

Department of Chemistry-Ångström Laboratory, Uppsala University, SE-75121 Uppsala, Sweden

\begin{abstract}
High lithium cycling efficiencies are required if a metal anode system is to be considered for use in $\mathrm{Li}-\mathrm{O}_{2}$ batteries. In this work electrolyte additives $\left(0.3 \mathrm{M} \mathrm{LiNO}_{3}\right.$ and $\left.0.14 \mathrm{M} \mathrm{VC}\right)$ were used to increase the efficiency from 25 to $82.5 \%$ in the topical DMSO based electrolyte. Furthermore, we show that oxygen also acts to improve the cycling efficiency to $87 \%$. This work highlights the importance of anode considerations in the development of metal $\mathrm{O}_{2}$ batteries in alternative solvents (DMSO, Acetonitrile and DMA) and suggests realistic strategies for performance improvements.

(C) The Author(s) 2014. Published by ECS. This is an open access article distributed under the terms of the Creative Commons Attribution 4.0 License (CC BY, http://creativecommons.org/licenses/by/4.0/), which permits unrestricted reuse of the work in any medium, provided the original work is properly cited. [DOI: 10.1149/2.007406eel] All rights reserved.
\end{abstract}

Manuscript submitted March 5, 2014; revised manuscript received April 3, 2014. Published April 18, 2014.

The goal of a rechargeable Li- $\mathrm{O}_{2}$ battery has stimulated many research studies in recent years. Practical estimates suggest that this system could provide a 2 to 5 times increase in energy density over current technologies. ${ }^{1-3}$ Ideal systems reduce oxygen during discharge (oxygen reduction reaction; ORR) forming of $\mathrm{Li}_{2} \mathrm{O}_{2}$ which precipitates in the cathode architecture. Then on charging oxidize the $\mathrm{Li}_{2} \mathrm{O}_{2}$ to form oxygen gas and lithium ions (oxygen evolution reaction; OER). The majority of studies have focused on lithium metal as the negative electrode (exceptions are silicon ${ }^{4}$ or $\mathrm{LiFePO}_{4}{ }^{5}$ validation studies); here lithium metal is oxidized during discharge to form $\mathrm{Li}$ ions in solution which are then reduced back to metallic lithium on charge. The development of $\mathrm{Li}-\mathrm{O}_{2}$ batteries has been hampered by difficulties finding a stable electrolyte which allows these reactions to occur without accompanying decomposition. ${ }^{1,2,6,7}$ Many solvent systems have been investigated; with the majority of focus being on carbonates and ethers. However, carbonate solvents have been shown to have unstable cathode and anode performance. ${ }^{8-12}$ Research into ether based solvents was initially more promising with the formation of $\mathrm{Li}_{2} \mathrm{O}_{2}$ clearly demonstrated. ${ }^{13,14}$ However, sustained stable cycling has not been conclusively established. ${ }^{15-17}$ This combined with the instability of ethers to $\mathrm{Li}_{2} \mathrm{O}_{2}$ as well as auto-oxidation reactions suggests that this solvent system is also unrealistic. ${ }^{18-20}$

Recently studies have demonstrated solvent stability during cycling in dimethylsulfoxide (DMSO), acetonitrile and N,Ndimethylacetamide (DMA) electrolytes. ${ }^{21-25}$ However, these solvents are also known to be unstable in contact with lithium, therefor making the construction of real cells problematic.

One of the most promising candidate electrolytes is dimethylsulfoxide (DMSO). ${ }^{23-26}$ However, the stability of the lithium metal electrode in contact with this electrolyte has been questioned (the effect of which is negated in proof of concept cells where a large excess of Li is used). This instability is because the reduction products of DMSO and the lithium salt do not form a stable passivation layer on the metal surface. In this short letter we aim to highlight the concept of using electrolyte additives which can participate in the formation of an effective SEI layer which will act to protect the surface of the lithium metal.

The effect of having an unstable SEI layer on the surface of the lithium metal will be to achieve an extremely poor cycling efficiency. If a stable SEI layer on the lithium is not formed a reaction with the electrolyte (unstable $<0.8 \mathrm{~V}$ vs. $\mathrm{Li} / \mathrm{Li}^{+}$) will continue until the available lithium has been fully oxidized. Therefore, if a fixed amount of lithium is plated in the absence of a robust SEI layer (it is worth noting that in the experiment under consideration here plating is still possible implying that an SEI layer is somewhat present which sup-

\footnotetext{
*Electrochemical Society Active Member.

** Electrochemical Society Student Member.

${ }^{\text {zE} E-m a i l: ~ m r r 372 @ g m a i l . c o m ~}$
}

presses continuous direct electro-reduction of the electrolyte which would significantly hamper a galvanostatic plating experiments) given time the lithium will be consumed from reaction with the electrolyte, if then an oxidizing current is applied to strip the remaining lithium only a small fraction of the plating charge will be seen resulting in a low efficiency. If higher efficiencies are observed this indicates that a more stable SEI layer has formed which inhibits consumption of the deposit from the electrolyte (assuming that a stable SEI layer does not consume large quantities of Li during formation). Therefore, we investigate the lithium plating and cycling efficiency (in isolation from the cathode chemistry) as a measure of the quality of the SEI layer formed and thus the stability of the lithium metal in DMSO based electrolytes. Additionally we investigate the effect of the electrolyte additives $\left(\mathrm{VC}, \mathrm{LiNO}_{3}\right.$ and $\mathrm{O}_{2}$ ) on the cycling efficiency and thus the quality of the SEI layer. The choice of $\mathrm{VC}$ and $\mathrm{LiNO}_{3}$ additives used in these studies was motivated by previous reports within the literature pertaining to their use in SEI formation. VC additives have been used to improve the SEI layer on graphite electrodes ${ }^{27}$ and $\mathrm{LiNO}_{3}$ has been used by those studying Li-S batteries. ${ }^{28}$ Additionally, $\mathrm{LiNO}_{3}$ has been used in DMA electrolytes where in combination with oxygen forms a stable SEI layer. ${ }^{22}$ We also chose to make the efficiency measurements both in the presence and absence of dissolved oxygen, to simulate the environments in both a standard lithium battery and $\mathrm{Li}-\mathrm{O}_{2}$ cell.

\section{Experimental}

A summary of the experiments conducted is given below, however, a detailed account can be found in the supplementary information. The electrochemical measurements were made under galvanostatic control using a two electrode cell with a large Li counter electrode and copper mesh working electrode separated by an electrolyte soaked glass fiber separator which could be exposed to an oxygen atmosphere. The electrolyte was either $1 \mathrm{M} \mathrm{LiClO}_{4}$ in DMSO simply referred to as DMSO electrolyte and one containing $1 \mathrm{M} \mathrm{LiClO}_{4}, 0.3 \mathrm{M} \mathrm{LiNO}_{3}$ and $0.14 \mathrm{M}$ VC in DMSO simply referred to as DMSO plus $\mathrm{LiNO}_{3}$ and VC. Both these electrolyte combinations were tested in the presence and absence of saturation levels of dissolved $\mathrm{O}_{2}$. Two regimes were used for testing:

- Regime 1; A fixed current $\left(1.76 \mathrm{~mA} \mathrm{~cm}^{-2}\right)$ was applied to $1 \mathrm{~cm}^{2}$ disk of copper mesh until $2.5 \mathrm{C}$ (equal to $0.88 \mathrm{mAh} \mathrm{cm}^{-2}$ ) of charge had passed. This plated lithium was then stripped galvanostatically after a 5 minute rest period.

- Regime 2; A fixed amount of Lithium is plated on the surface of $\mathrm{Cu}$ mesh (3.6 C or $1 \mathrm{mAh}$ ). A fraction of the lithium metal $0.31 \mathrm{C}$ $(\sim 10 \%)$ (we chose this as it was 5 minutes at $\left.1.3 \mathrm{mAh} \mathrm{cm}^{-2}\right)$ is then stripped and re-plated continually until an end point was observed when $1 \mathrm{~V}$ vs. $\mathrm{Li}$ was reached. This regime is closer to the conditions in a real battery. 

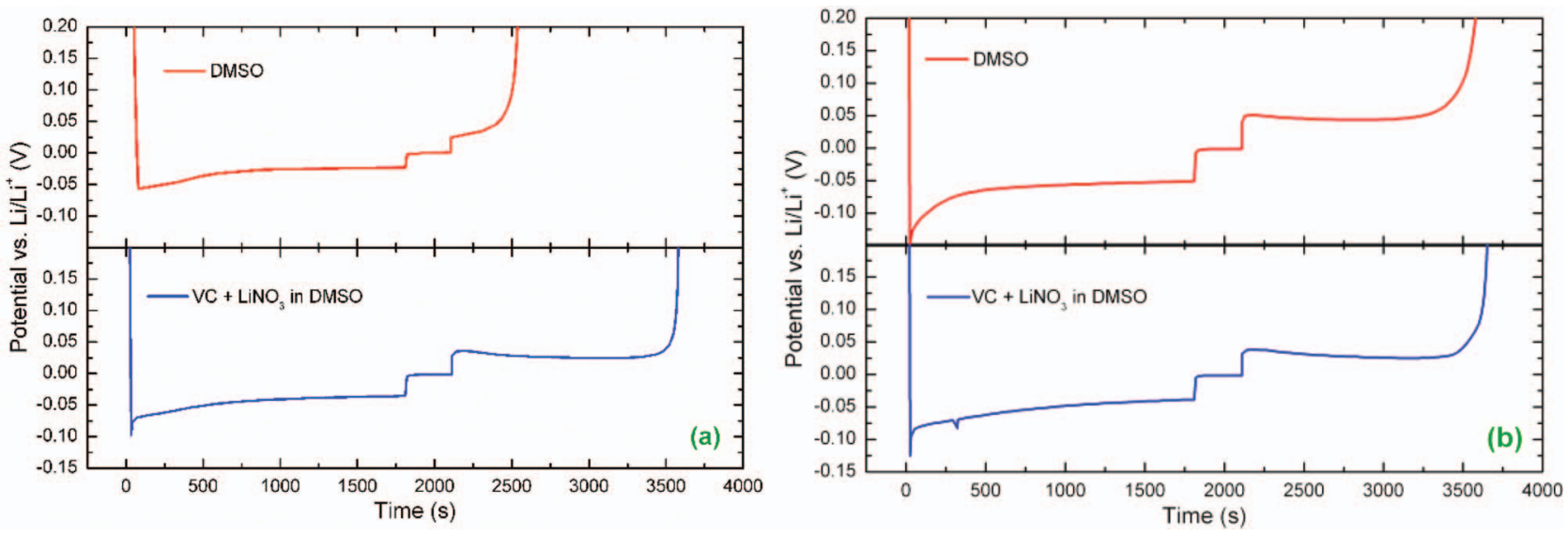

Figure 1. Lithium plating and stripping reactions (Regime 1) in DMSO electrolytes with and without additives. Results in both an oxygen free (a) and oxygen saturated (b) electrolytes are shown. The charge passed during the negative current step was $0.88 \mathrm{mAh} \mathrm{cm}{ }^{-2}$.

Additional information about other measurements including X-ray photo electron spectroscopy (XPS) and X-ray diffraction (XRD) can also be found in the supplementary information.

\section{Results and Discussion}

The potential vs. time profiles for all additive combinations tested under Regime 1 are shown in Figure 1; in all cases on application of a negative current the potential of the cell dropped from the open circuit voltage $\left(\sim 2.9 \mathrm{~V}\right.$, hereafter all the voltages are presented vs. $\left.\mathrm{Li} / \mathrm{Li}^{+}\right)$ to around $-0.15 \mathrm{~V}$ (some variability is observed in the potential plateau which we attribute to the variable nature of the SEI layer changing the resistance within the cell), some features in the potential profile consistent with the degradation of the electrolyte were observed during this initial period. After reaching $-0.15 \mathrm{~V}$ the potential slowly changed to a plateau at around $-0.1 \mathrm{~V}$, this is attributed to initial over potentials required to provide nucleation sites on the copper surface, the potential then remains stable for the duration of the plating step (evidence of the formation of $\mathrm{Li}$ metal is provided in the form of XRD patterns shown in the supplementary information Figure S1). During the stripping reaction a flat plateau region $(\sim 0.05 \mathrm{~V})$ followed by a sharp increase to $1 \mathrm{~V}$ was observed; when $1 \mathrm{~V}$ was reached the stripping cycle was considered complete. It can be seen in Figure 1a (top) that in an electrolyte composed of only $\mathrm{LiClO}_{4}$ in DMSO the efficiency is extremely low (25\%). The poor efficiency in DMSO indicates that a stable SEI layer has not formed on the lithium metal which continues to react with the electrolyte consuming the majority of the deposit (as explained above). When the additives were used (Figure 1a (bottom)) the efficiency could be increased to $82.5 \%$ which we propose is a result of the reduction of $\mathrm{VC}$ and $\mathrm{LiNO}_{3}$ forming a stable SEI layer.

The effect of saturation levels of oxygen in the DMSO and DMSO plus $\mathrm{VC}$ and $\mathrm{LiNO}_{3}$ electrolytes on the lithium plating efficiency is shown in Figure 1b. When oxygen saturated the efficiency in the DMSO (Figure 1b (top)) electrolyte increased from 25 to $85 \%$. This suggests that a passivation layer has been formed on the metal surface. Since we have identified that this cannot be the case in DMSO we suggest that this is resulting from the reduction of oxygen and the formation of $\mathrm{Li}_{2} \mathrm{O}_{2}$ or possibly $\mathrm{Li}_{2} \mathrm{O}$. The effect of oxygen on the DMSO plus VC and $\mathrm{LiNO}_{3}$ (Figure $1 \mathrm{~b}$ (bottom)) was less significant improving the efficiency from $82.5 \%$ to $87 \%$ (these measurements were repeated several times with the spread of results no greater than $1 \%$ making this a small but statistically real increase).

The same electrolyte combinations were then examined under the electrochemical conditions described in regime 2 in the experimental section. In this experiment the greater the number of cycles achieved by a cell the more stable the electrolyte is to reaction with the lithium metal. Conversely, for cells where a lower number of cycles are achieved we can infer that there must be parasitic side reactions with the electrolyte consuming the excess lithium. The voltage time profiles from these experiments for all electrolytes and additive combinations are shown in Figure 2. The characteristic plating period is similar to that seen for the results presented in Figure 1, however, this is now followed by small periods of plating and stripping. These results highlight the poor cycling efficiency in pure DMSO electrolyte where only 5 cycles were achieved before all the available lithium was depleted. However, again the addition of additives significantly improved the efficiency with 25,27 and 33 cycles achieved for the i) DMSO plus $\mathrm{VC}$ and $\mathrm{LiNO}_{3}$, ii) DMSO plus $\mathrm{O}_{2}$ and iii) DMSO plus VC, $\mathrm{LiNO}_{3}$ and $\mathrm{O}_{2}$ respectively (See figure $\mathrm{S} 2$ for results of a similar experiment conducted in a standard ethylene carbonate/diethylene carbonate).

X-ray photoelectron spectroscopy (XPS) analysis of Li metals kept in the DMSO solutions with and without the additives confirmed that $\mathrm{VC}$ and $\mathrm{LiNO}_{3}$ contributed to the formation of a passivation layer on $\mathrm{Li}$ metals (Figure 3). This was seen as changes in the carbon and nitrogen

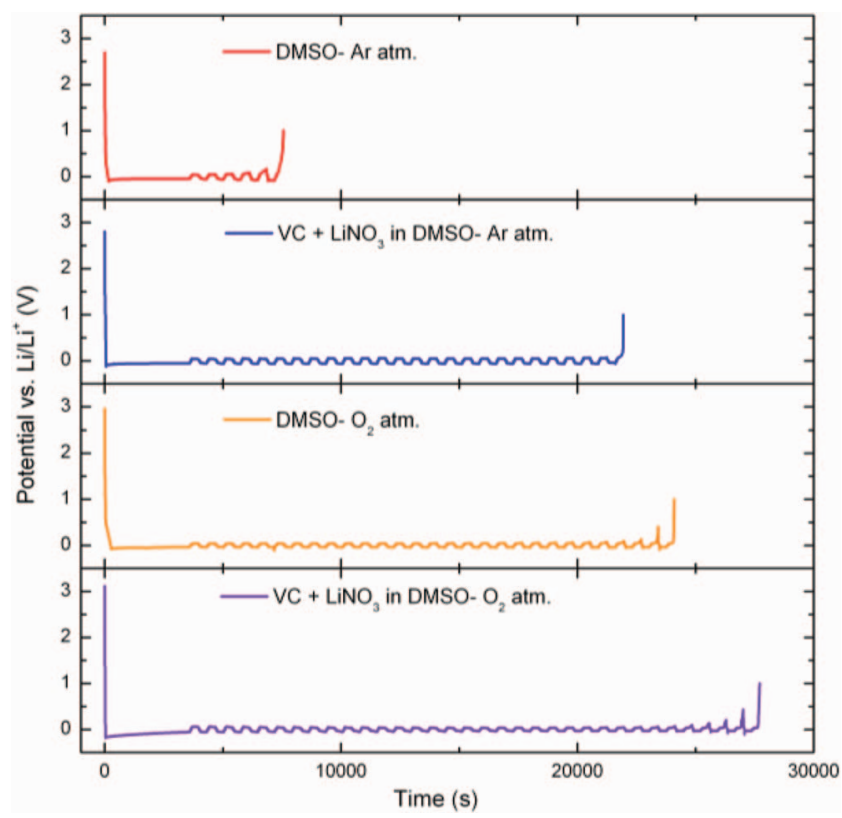

Figure 2. Voltage vs. time profiles for lithium plating and stripping reactions under cycling regime 2. Results are shown for DMSO electrolytes with and without additives and in the presence and absence of oxygen. 


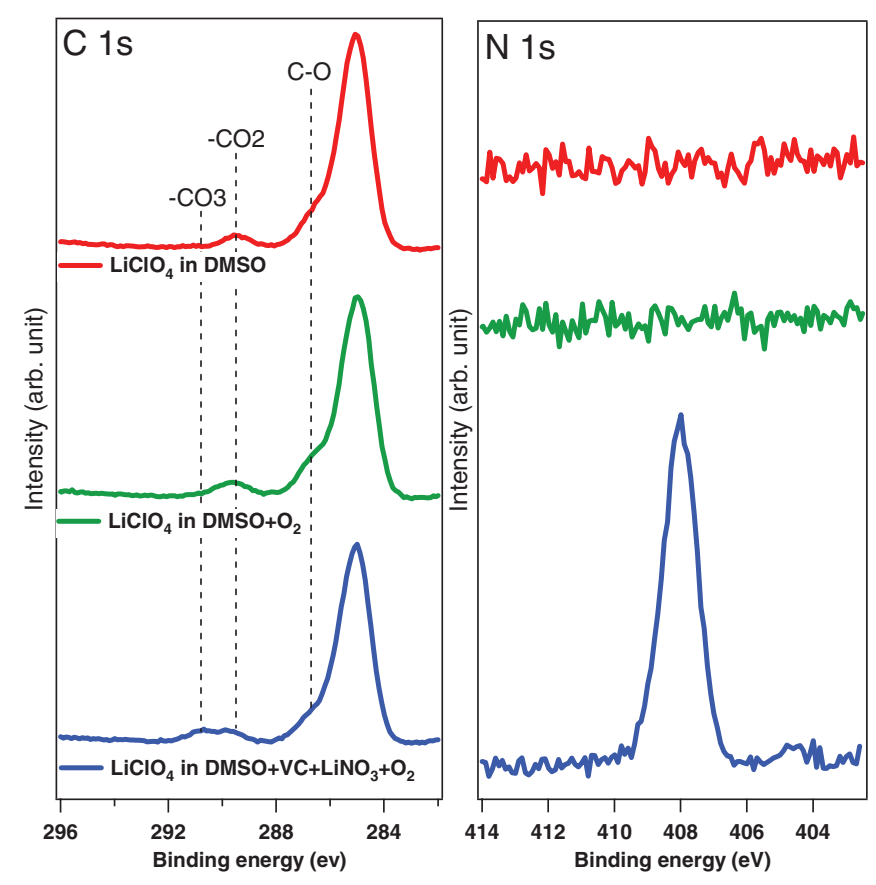

Figure 3. $\mathrm{C} 1 \mathrm{~s}$ and $\mathrm{N} 1 \mathrm{~s}$ spectra of Li metals kept in the DMSO solutions with and without the additives.

spectra. The $\mathrm{C} 1 \mathrm{~s}$ and $\mathrm{N}$ 1s spectra of the sample with the additive contain a small carbonate peak at $\sim 291 \mathrm{eV}$ (resulting from VC) and a main peak at $\sim 408 \mathrm{eV}$ (resulting from $\mathrm{LiNO}_{3}$ ), respectively. ${ }^{27-29} \mathrm{In}$ addition to the additives the $\mathrm{S} 2 \mathrm{p}, \mathrm{Cl} 2 \mathrm{p}$, and $\mathrm{O}$ 1s XPS spectra indicate that solvent and salt also contributed to the components found in the SEI on Li metal in all the samples (Figure S3). ${ }^{12,30}$ Additional PES data concerning the SEI formed on the copper mesh during lithium plating is provided in Figure S4.

The increased stabilization seen in the electrochemical data and the results of the XPS data suggest that the use of the $\mathrm{VC}, \mathrm{LiNO}_{3}$ and $\mathrm{O}_{2}$ act to form passive films of the surface of the Lithium metal. We propose that this results from the formation of the following solid reduction products:

- Poly(ethylene oxide) (PEO) like materials or ROLi: formed from reduction of $\mathrm{VC}$ as seen in most carbonate based electrolytes. ${ }^{27}$

- $L i_{x} N O_{y}$ : formed from the reduction of $\mathrm{LiNO}_{3}$. This has been well studied as a means of stabilizing the surface of lithium metal in electrolytes for Li-S batteries. ${ }^{22,28,31}$

- $\mathrm{Li}_{2} \mathrm{O}_{2}$ or $\mathrm{Li}_{2} \mathrm{O}$ : formed from the reduction of Oxygen. ${ }^{32}$

The listed products are likely candidates for species in the SEI layer, however, in this complicated chemical situation with many reactive components there may be many other possible reaction pathways that could lead to alternative products. However, what is clear is that a dramatic stabilization effect is observed in DMSO electrolytes when additives are used.

Based on the above results one may conclude that the use of oxygen as an additive is sufficient to stabilize the surface and the use of the other additives is redundant in a $\mathrm{Li}-\mathrm{O}_{2}$ battery. This is in agreement with results in a DMA electrolyte. ${ }^{33}$ In a final experiment presented in Figure 4 we highlight the fact that although an oxygen additive is effective in stabilizing the lithium this is only the case if oxygen is present at the point of cell construction. In the majority of research labs $\mathrm{Li}-\mathrm{O}_{2}$ batteries are built within a water and oxygen free glove box and then cycled in an oxygen atmosphere. The absence of the oxygen during the initial cell construction will mean that the lithium metal will continue to react and consume the electrolyte until the cell is exposed

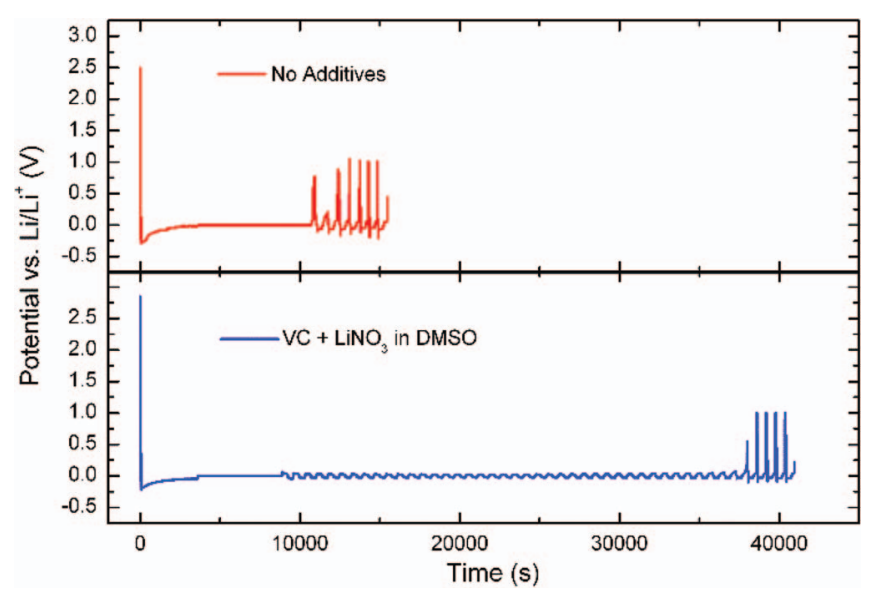

Figure 4. Voltage vs. time profiles for lithium plating and stripping reactions under cycling regime 2. Results are shown for DMSO electrolytes with and without additives. Plating was conducted under an argon atmosphere and then the cells were exposed to oxygen for 120 mins before the cycling regime was continued.

to an oxygen atmosphere. We examine this effect (Figure 4) by looking at two cells one with DMSO electrolyte and the other with DMSO plus $\mathrm{VC}$ and $\mathrm{LiNO}_{3}$ additives. Lithium was deposited in an oxygen free environment and left for 120 minutes before exposure to an oxygen atmosphere. In the pure DMSO electrolyte no cycles without reaching limiting potentials were achieved. However, the additives increased the number of cycles to 41 . This demonstrates that if built using a conventional construction in an argon glove box the additives are required to prevent reaction between the lithium metal counter electrode and the electrolyte.

\section{Conclusions}

In conclusion, we have shown that whilst DMSO based electrolytes are not stable in contact with lithium it is possible to use a combination of electrolyte additives to form significantly improved passive films on the metal surface. This surface layer is formed in situ and should if damaged be self-healing and aid long term cycling. Utilizing this approach we suggests that it may be possible to improve the lithium cycling performance to a level similar to that observed in conventional battery electrolytes. This additive approach may also be applied to stabilizing the SEI layer in other anode based systems under consideration for $\mathrm{Li}$ ion- $\mathrm{O}_{2}$ batteries such as $\mathrm{Si}$, graphite or $\mathrm{Sn}$ as ultimately if stable SEI layers cannot be formed on anode materials sustained cycling of $\mathrm{O}_{2}$ batteries will not be achieved. On materials such as $\mathrm{Si}$, graphite or $\mathrm{Sn}$ electrodes this kind of additive approach may be even more effective as there is no dendritic lithium growth which severely hampers the performance of metal anodes. This work provides a first step into the development of such electrolyte formulations and provides a framework of experimental strategies for further study. We hope that this work will influence researchers focused on cathode chemistry such that the effect of these additives on the full cell performance can be characterized and understood.

Additionally, this work impacts on studies in lithium ion cells where with the correct additive combination solvents beyond the conventional carbonate based variety may be considered. It also highlights the useful role in SEI formation that oxygen can play and suggests that this effect should be studied further in other electrolyte systems.

\section{Acknowledgments}

We acknowledge the support of the Swedish Research Council (VR), The Swedish Energy Agency (STEM) and Uppsala University (StandUp for Energy). 


\section{References}

1. P. G. Bruce, S. A. Freunberger, L. J. Hardwick, and J.-M. Tarascon, Nat. Mater., 11, 19 (2012).

2. Y.-C. Lu, B. M. Gallant, D. G. Kwabi, J. R. Harding, R. R. Mitchell, M. S. Whittingham, and Y. Shao-Horn, Energy Environ. Sci., 6, 750 (2013).

3. F. Li, T. Zhang, and H. Zhou, Energy Environ. Sci., 6, 1125 (2013).

4. J. Hassoun, H.-G. Jung, D.-J. Lee, J.-B. Park, K. Amine, Y.-K. Sun, and B. Scrosati, Nano Lett., 12, 5775 (2012).

5. B. D. McCloskey, D. S. Bethune, R. M. Shelby, T. Mori, R. Scheffler, A. Speidel, M. Sherwood, and A. C. Luntz, J. Phys. Chem. Lett., 3, 3043 (2012).

6. F. Cheng and J. Chen, Chem. Soc. Rev., 41, 2172 (2012).

7. J. Christensen, P. Albertus, R. S. Sanchez-Carrera, T. Lohmann, B. Kozinsky, R. Liedtke, J. Ahmed, and A. Kojic, J. Electrochem. Soc., 159, R1 (2012).

8. R. Younesi, S. Urbonaite, K. Edström, and M. Hahlin, J. Phys. Chem. C, 116, 20673 (2012).

9. J. Xiao, J. Hu, D. Wang, D. Hu, W. Xu, G. L. Graff, Z. Nie, J. Liu, and J.-G. Zhang, J. Power Sources, 196, 5674 (2011).

10. J.-L. Shui, J. S. Okasinski, D. Zhao, J. D. Almer, and D.-J. Liu, ChemSusChem, 5, 2421 (2012).

11. R. Younesi, M. Hahlin, M. Roberts, and K. Edström, J. Power Sources, 225, 40 (2013).

12. R. Younesi, M. Hahlin, and K. Edström, ACS Appl. Mater. Interfaces, 5, 1333 (2013).

13. B. D. McCloskey, R. Scheffler, A. Speidel, D. S. Bethune, R. M. Shelby, and A. C. Luntz, J. Am. Chem. Soc., 133, 18038 (2011).

14. Y.-C. Lu, D. G. Kwabi, K. P. C. Yao, J. R. Harding, J. Zhou, L. Zuin, and Y. Shao- Horn, Energy Environ. Sci., 2999 (2011).

15. S. A. Freunberger, Y. Chen, N. E. Drewett, L. J. Hardwick, F. Bardé, and P. G. Bruce, Angew. Chemie Int. Ed., 50, 8609 (2011).
16. R. Younesi, M. Hahlin, M. Treskow, J. Scheers, P. Johansson, and K. Edström, J. Phys. Chem. C, 116, 18597 (2012).

17. H. Wang and K. Xie, Electrochim. Acta, 64, 29 (2012).

18. R. Younesi, M. Hahlin, F. Björefors, P. Johansson, and K. Edström, Chem. Mater. 25, 77 (2013).

19. L. G. Wade, Organic Chemistry, 7th ed., Pearson Prentice Hall, 2010.

20. A. M. Clover, J. Am. Chem. Soc., 44, 1107 (1922).

21. C. O. Laoire, S. Mukerjee, K. M. Abraham, E. J. Plichta, and M. A. Hendrickson, J. Phys. Chem. C, 113, 20127 (2009).

22. W. Walker, V. Giordani, J. Uddin, V. S. Bryantsev, G. V Chase, and D. Addison, J. Am. Chem. Soc., 135, 2076 (2013).

23. M. J. Trahan, S. Mukerjee, E. J. Plichta, M. A. Hendrickson, and K. M. Abraham, J. Electrochem. Soc., 160, A259 (2013).

24. Z. Peng, S. A. Freunberger, Y. Chen, and P. G. Bruce, Science, 337, 563 (2012).

25. D. Xu, Z. Wang, J. Xu, L. Zhang, and X. Zhang, Chem. Commun., 48, 6948 (2012).

26. H. Lee, D. J. Lee, J-.N. Lee, J. Song, Y. Lee, M-.H. Ryou, J-.K. Park, and Y. M. Lee, Electrochim. Acta, 123, 419 (2014).

27. M. Herstedt, A. M. Andersson, H. Rensmo, H. Siegbahn, and K. Edström, Electrochim. Acta, 49, 4939 (2004).

28. D. Aurbach, E. Pollak, R. Elazari, G. Salitra, C. S. Kelley, and J. Affinito, J. Electrochem. Soc., 156, A694 (2009).

29. L. El Ouatani, R. Dedryvère, C. Siret, P. Biensan, S. Reynaud, P. Iratcabal, and D. Gonbeau, J. Electrochem. Soc., 156, A103 (2009).

30. R. Younesi, P. Norby, and T. Vegge, ECS Electrochem. Lett., 3, A15 (2014).

31. J. Poris, I. Raistrick, and R. A. Huggins, Proc. Electrochem. Soc., 313, 84 (1984).

32. H. Ye, J. Huang, J. J. Xu, A. Khalfan, and S. G. Greenbaum, J. Electrochem. Soc., 154, A1048 (2007).

33. V. Giordani, W. Walker, V. S. Bryantsev, J. Uddin, G. V Chase, and D. Addison, J. Electrochem. Soc., 160, A1544 (2013) 